\title{
Adsorptive Removal of Methylene Blue Using Groundnut Shell Activated Carbon Coated With $\mathrm{Fe}_{2} \mathrm{O}_{3}$
}

\author{
S.S. Imam ${ }^{1,2^{*}}$ and M. Abdullahi ${ }^{1}$ \\ ${ }^{1}$ Department of Chemistry, SRM University, Kattankulathur-603203, Tamil Nadu, India. \\ ${ }^{2}$ Department of Pure and Industrial Chemistry, Bayero University, P.M.B 3011, Kano, Nigeria.
}

\begin{abstract}
In this work, activated carbon prepared from groundnut shells (GSAC) by sulphuric acid treatment was coated with $\mathrm{Fe}_{3} \mathrm{O}_{4}\left(\mathrm{GSAC}-\mathrm{Fe}_{3} \mathrm{O}_{4}\right)$ and tested for its efficiency as an adsorbentfor the removal of methylene blue $(M B)$ dye from aqueous solution. The structural morphology and functional groups present were investigated using scanning electron microscope (SEM) and Fourier transform infrared (FTIR) spectroscopy. Various sorption parameters such as effect of $\mathrm{pH}$, contact time, initial dye concentration and adsorbent dosage were studied. The percentage removal of methylene blue increased with decrease in initial methylene blue concentration and increased with increase in contact time and dose of the adsorbent. Equilibrium data were analysed using Langmuir and Freundlich isotherm models. Kinetic data were studied using pseudo-first order and pseudo-second order kinetic models.
\end{abstract}

Keywords: GSAC, GSAC- $\mathrm{Fe}_{3} \mathrm{O}_{4}, \mathrm{MB}$, Isotherm, Kinetics.

\section{Introduction}

Many industries such as paper, plastics, cosmetics, detergents, leather, pharmaceutical and food industries make extensive use of dye stuffs in their production processes. These industries are continuously discharging effluents containing dyes and their breakdown products which are toxic to living organisms into the ecosystem ${ }^{[1-2]}$. These dyes are visually detected even at low concentration and can significantly affect photosynthetic activity in aquatic life due to reduced light penetration ${ }^{[3]}$. Therefore, decolourisation of dyes is an important aspect of wastewater treatment before discharge ${ }^{[4]}$.

Several treatment methods such as biological, chemical and physiochemical are used for the removal of dyes from wastewater, but most of these methods have serious restrictions such as formation of hazardous byproducts, intensive energy requirement or high cost ${ }^{[5]}$. Adsorption onto activated carbon is one of the most effective and efficient treatment techniques for the removal of dyes from wastewater, but commercially produced activated carbon is expensive ${ }^{[6]}$.Nowadays, many novel materials, mostly agricultural waste such as rice husk, pineapple peel, sawdust, yam fibre, maize cobs, coconut shell, neem leaf, mango seed carnal, vegetable waste, banana peeletc ${ }^{[31-37]}$. are been tested as adsorbents with the sole aim of finding much cheaper alternatives to activated carbon, but the adsorption capacities of some of the mentioned adsorbents is not very high. Hence, research trend is now geared towards improving the performance of these adsorbents using several modification methods ${ }^{[7-12]}$.

In this present study, groundnut shell activated carbon coated with $\mathrm{Fe}_{3} \mathrm{O}_{4}$ was tested as adsorbent for removal of methylene blue from aqueous solution.

\subsection{Preparation of Stock Solution of Methylene Blue Dye \\ II. Materials And Methods}

Methylene Blue dye [C.I. $=52015 \mathrm{~B}$; Chemical Formula $=\mathrm{C}_{6} \mathrm{H}_{18} \mathrm{ClN}_{3} \mathrm{~S}$; Molecular Weight $=373.91 \mathrm{~g}$; Melting Point $=100-110^{\circ} \mathrm{C}$ and $\left.\lambda_{\max }=660 \mathrm{~nm}\right]$ supplied by Avra Synthesis Pvt., Hyderabad, India was used as adsorbate without purification. A stock solution of $1000 \mathrm{mg} / \mathrm{L}$ MB dye was prepared by dissolving the appropriate amount of methylene blue in double distilled water. Experimental solutions of desired concentrations were obtained by dilution of stock solution using double distilled water.

\subsection{Preparation of Groundnut Shell Activated Carbon (GSAC)}

Groundnut shells were obtained from shelling units. These shells were washed with deionized water and dried in hot air oven at $120^{\circ} \mathrm{C}$ for 3 hours and then grounded into fine particles for easy activation. The activation was carried out in a beaker by soaking thoroughly $100 \mathrm{~g}$ of the dried sludge in $100 \mathrm{ml}$ of concentrated sulphuric acid and heated to $200^{\circ} \mathrm{C}$ with continuous agitation for 1 hour. After, agitation was then stopped and the mixture started to solidify producing a carbon like material. The resulting carbon was then allowed to cool to room temperature, washed with distilled water, soaked in dilute $\mathrm{NaOH}$ solution for 30 minutes and again washed with distilled water. The product was allowed to dry, sieved through $100 \mu \mathrm{m}$ sieve and stored in a closed container, ready for use. 


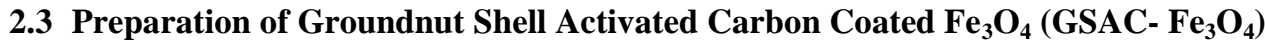

Chemical precipitation technique was employed here ${ }^{[13]}$. In this process, $2.1 \mathrm{~g}$ of $\mathrm{FeSO}_{4} .7 \mathrm{H}_{2} \mathrm{O}$ and $3.1 \mathrm{~g}$ of $\mathrm{FeCl}_{3} \cdot 6 \mathrm{H}_{2} \mathrm{O}$ were dissolved under inert atmosphere in $80 \mathrm{ml}$ of double distilled water with vigorous stirring using a mechanical stirrer. While the solution was heated to $80^{\circ} \mathrm{C}, 10 \mathrm{ml}$ of $\mathrm{NH}_{4} \mathrm{OH}$ solution (25\%) was added. To ensure complete growth, $10 \mathrm{~g}$ of the prepared groundnut shell activated carbon was added and reaction continued for 30 minutes. The resulting suspension was cooled down to room temperature and then repeatedly washed with distilled water to remove unreacted chemicals. The product was dried in an oven at $50^{\circ} \mathrm{C}$ for $2 \mathrm{~h}$, tested using a magnetic rod and then stored in a closed container ready for use. The reactions that occur in the production are shown in chemical equations (1) and (2).

$$
\begin{aligned}
\mathrm{FeSO}_{4} \cdot 7 \mathrm{H}_{2} \mathrm{O} & +2 \mathrm{FeCl}_{3} \cdot 6 \mathrm{H}_{2} \mathrm{O}+8 \mathrm{NH}_{4} \mathrm{OH} \\
\mathrm{Fe}_{3} \mathrm{O}_{4}+\mathrm{GSAC} & \rightarrow \mathrm{Fe}_{3} \mathrm{O}_{4}+6 \mathrm{HH}_{4} \mathrm{Ol}+\left(\mathrm{NH}_{4}\right)_{2} \mathrm{SO}_{4}+17 \mathrm{H}_{2} \mathrm{O}(1)
\end{aligned}
$$

\subsection{Adsorption Experiments}

All adsorption experiments were carried out by batch techniques at room temperature on a mechanical shaker at $150 \mathrm{rpm}$ using $250 \mathrm{ml}$ capped conical flasks. The influence of $\mathrm{pH}(3,5,7,9$ and 11) was varied by adding $0.1 \mathrm{M} \mathrm{NaOH}$ or $0.1 \mathrm{M} \mathrm{HCl}$ for adjustment and measured using a pH meter (Systronics made), adsorbent dosage $(0.1,0.2,0.3,0.4$ and $0.5 \mathrm{~g})$, initial methylene blue concentration $(50,100,150,200$ and $300 \mathrm{mg} / \mathrm{L})$ and contact time $(10,30,60,90$ and $120 \mathrm{~min})$ on the performance of $\mathrm{GSAC}-\mathrm{Fe}_{3} \mathrm{O}_{4}$ were evaluated. After the adsorption process, the contents were filtered using a whatman filter paper no. 42 and the supernatant solution was analysed using a UV-visible spectrophotometer (Elico Model No: SL210) by recording the absorbance changes at wavelength of $660 \mathrm{~nm}$. The amount of $\mathrm{MB}$ dye adsorbed per unit weight of GSAC- $\mathrm{Fe}_{3} \mathrm{O}_{4}$ adsorbent at time ' $\mathrm{t}^{\prime}, \mathrm{q}_{\mathrm{t}}(\mathrm{mg} / \mathrm{L})$ and percentage $\mathrm{MB}$ dye adsorption capacity was calculated using equations (3) and (4):

$$
\begin{aligned}
& \text { Amount of MB adsorbed }\left(\mathrm{q}_{\mathrm{t}}\right)=\frac{\mathrm{V}\left(\mathrm{C}_{\mathrm{o}}-\mathrm{C}_{\mathrm{t}}\right)}{m} \\
& \text { Percentage removal of MB }=\frac{\mathrm{C}_{o}-\mathrm{C}_{\mathrm{t}}}{\mathrm{C}_{\mathrm{t}}} \times 100
\end{aligned}
$$

Where $\mathrm{C}_{\mathrm{o}}$, is the initial MB dye concentration $(\mathrm{mg} / \mathrm{L}), \mathrm{C}_{\mathrm{t}}$ is the concentration of MB dye at any time $\mathrm{t}, \mathrm{Vis}$ the volume of solution $(\mathrm{ml})$ and mis the mass of $\mathrm{GSAC}-\mathrm{Fe}_{3} \mathrm{O}_{4}(\mathrm{gm})$.

\subsection{Characterisation of Adsorbent \\ 3.1.1 FTIR Characterisation}

Fourier transform infrared spectroscopy of the adsorbent was done by using an FTIR spectrophotometer (model: FTIR Bruker IFS 66V). The FTIR spectra of GSAC, GSAC-Fe $\mathrm{O}_{4}$ and GSAC$\mathrm{Fe}_{3} \mathrm{O}_{4}-\mathrm{MB}$ were recorded in the range of $4000 \mathrm{~cm}^{-1}$ to $400 \mathrm{~cm}^{-1}$ using $\mathrm{KBr}$ disc for reference. The essence is to ascertain the possible involvement of functional groups on the surface of GSAC when coated with $\mathrm{Fe}_{3} \mathrm{O}_{4}$ and in adsorption of MB. Figure 2(a) shows the spectrum of GSAC. Several number of absorption peaks were displayed indication the complex nature of GSAC. The band at $3412 \mathrm{~cm}^{-1}$ is due to bonded -OH groups ${ }^{[14]}$. The band observed at $2928 \mathrm{~cm}^{-1}$ could be assigned to the aliphatic C-H group.The trough at $1621 \mathrm{~cm}^{-1}$ represents the $\mathrm{C}=\mathrm{O}$ stretching mode conjugate with the $\mathrm{NH}_{2}{ }^{[15-16]}$. The $1208 \mathrm{~cm}^{-1}$ band was attributed to the vibration of $\mathrm{C}-\mathrm{O}$ in lignose; and the $1031 \mathrm{~cm}^{-1}$ band was attributed to the stretching vibrations of $\mathrm{C}-\mathrm{O}$ in cellulose and hemicellulose [17-19]. When comparing the spectra in figure 2(a) and (b), various functional groups were detected on the surface of the GSAC- $\mathrm{Fe}_{3} \mathrm{O}_{4}$ as shown in figure 2(b). An obvious observation also, was the shifting, disappearance or appearance of new peaks. Most importantly, the newer peak observed at $589 \mathrm{~cm}^{-1}$ is related to Fe-O group, and the peak around $3432 \mathrm{~cm}^{-1}$ was assigned to the $-\mathrm{OH}$ group on the surface of the magnetite. Figure 2(c) shows the FTIR spectrum after the adsorption of MB onto GSAC- $\mathrm{Fe}_{3} \mathrm{O}_{4}$. When comparing figure 2(b) and (c), figure 2(c) reveals that some new peaks appeared, some remained and some were shifted after MB adsorption. The bands at $3432 \mathrm{~cm}^{-1}, 2925 \mathrm{~cm}^{-1}, 1631 \mathrm{~cm}^{-1}, 1402 \mathrm{~cm}^{-1}$ and $589 \mathrm{~cm}^{-1}$ were shifted to $3417 \mathrm{~cm}^{-1}, 2924 \mathrm{~cm}^{-1}, 1596 \mathrm{~cm}^{-1}, 1385 \mathrm{~cm}^{-}$ ${ }^{1}$ and $584 \mathrm{~cm}^{-1}$ after $\mathrm{MB}$ adsorption. This is an indication that $\mathrm{OH}, \mathrm{C}-\mathrm{H}, \mathrm{C}=\mathrm{O}$ and $\mathrm{Fe}-\mathrm{O}$ groups could be involved in the adsorption of MB onto GSAC- $\mathrm{Fe}_{3} \mathrm{O}_{4}$. 

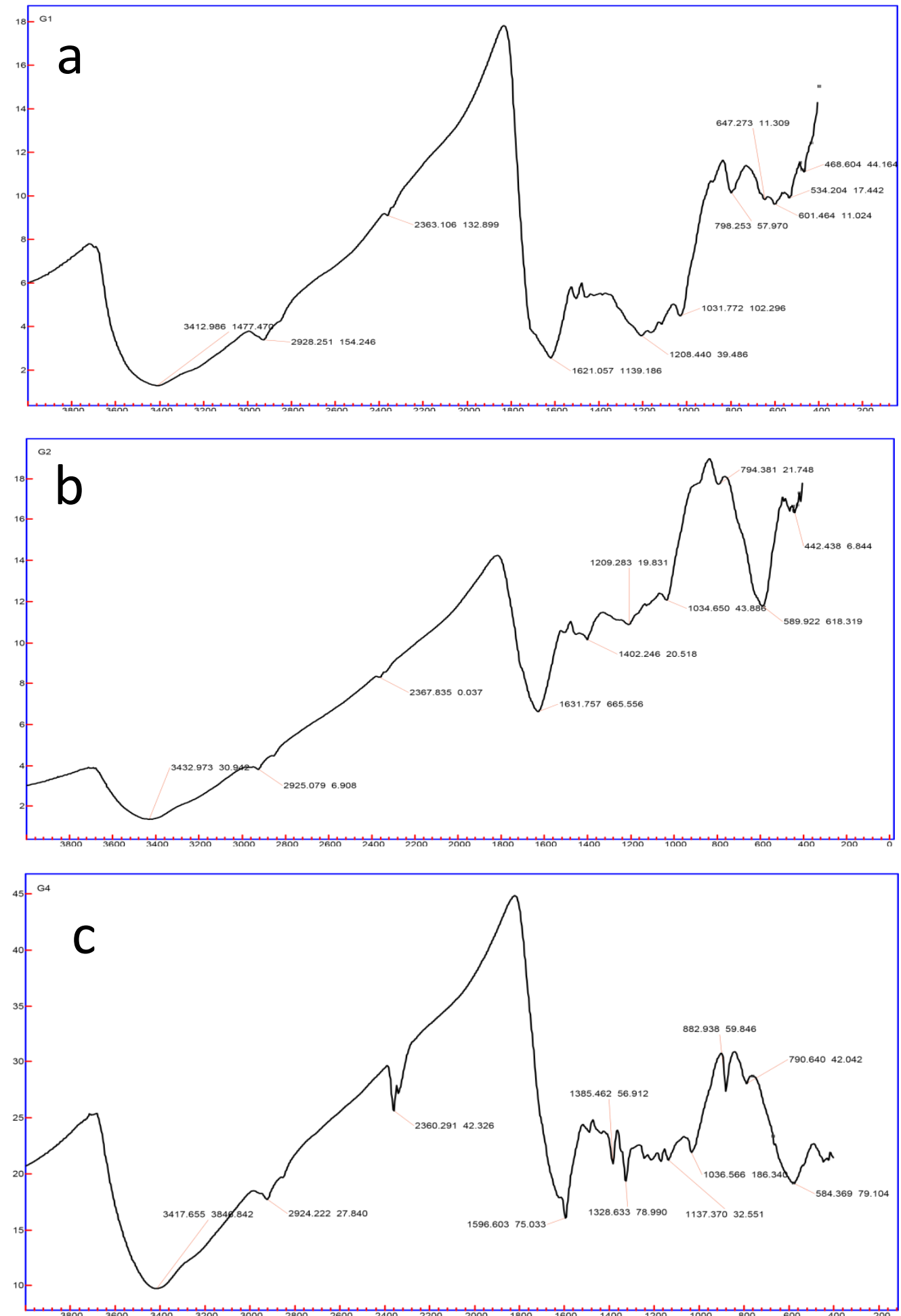

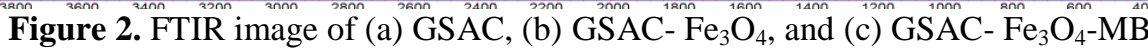

\subsubsection{SEM Characterisation}

Surface morphology of GSAC, GSAC- $\mathrm{Fe}_{3} \mathrm{O}_{4}$ and GSAC- $\mathrm{Fe}_{3} \mathrm{O}_{4}-\mathrm{MB}$ was visualised using Scanning Electron Microscopy (SEM).Measurements were taken using SEM-Quanta. The images were taken with an emission current of $100 \mu \AA$ by the Tungsten filament at a magnification of 15000xand an accelerator voltage of $20 \mathrm{kV}$. Figure 3(a), (b) and (c) shows the SEM micrographs of GSAC, GSAC- $\mathrm{Fe}_{3} \mathrm{O}_{4}$ and GSAC-Fe $\mathrm{O}_{4}-\mathrm{MB}$. The GSAC exhibits heterogeneous rough, dense and uneven surface morphology with a series of overlaps as shown in fig. 3(a). Fig. 3(b) shows the parent GSAC covered with $\mathrm{Fe}_{3} \mathrm{O}_{4}$. The surface of the dye loaded GSAC- $\mathrm{Fe}_{3} \mathrm{O}_{4}$ in fig. 3(c) shows the surface of $\mathrm{GSAC}-\mathrm{Fe}_{3} \mathrm{O}_{4}$ covered with dye molecules. 
Adsorptive Removal of Methylene Blue Using Groundnut Shell Activated Carbon Coated With $\mathrm{Fe}_{2} \mathrm{O}_{3}$
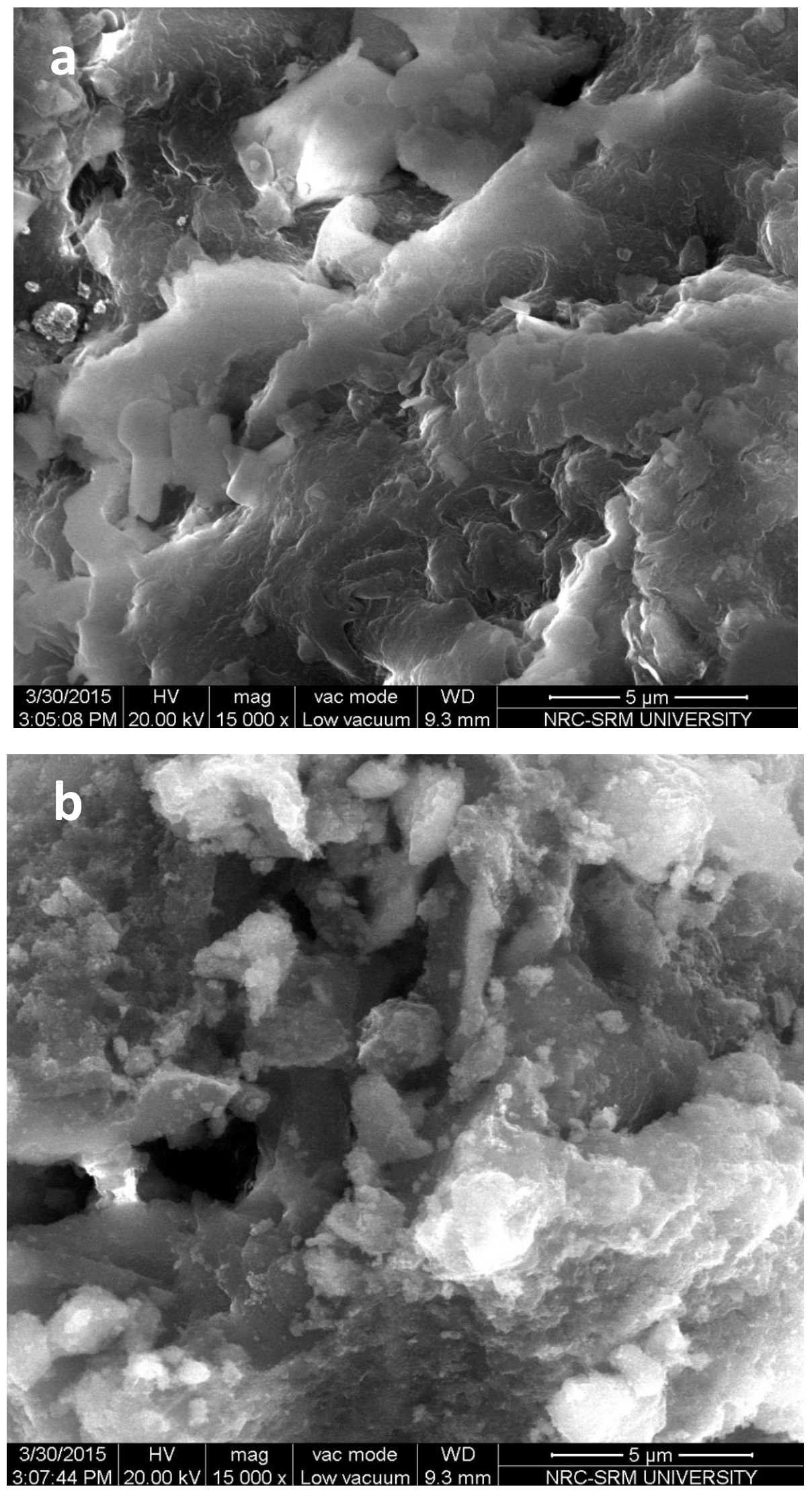


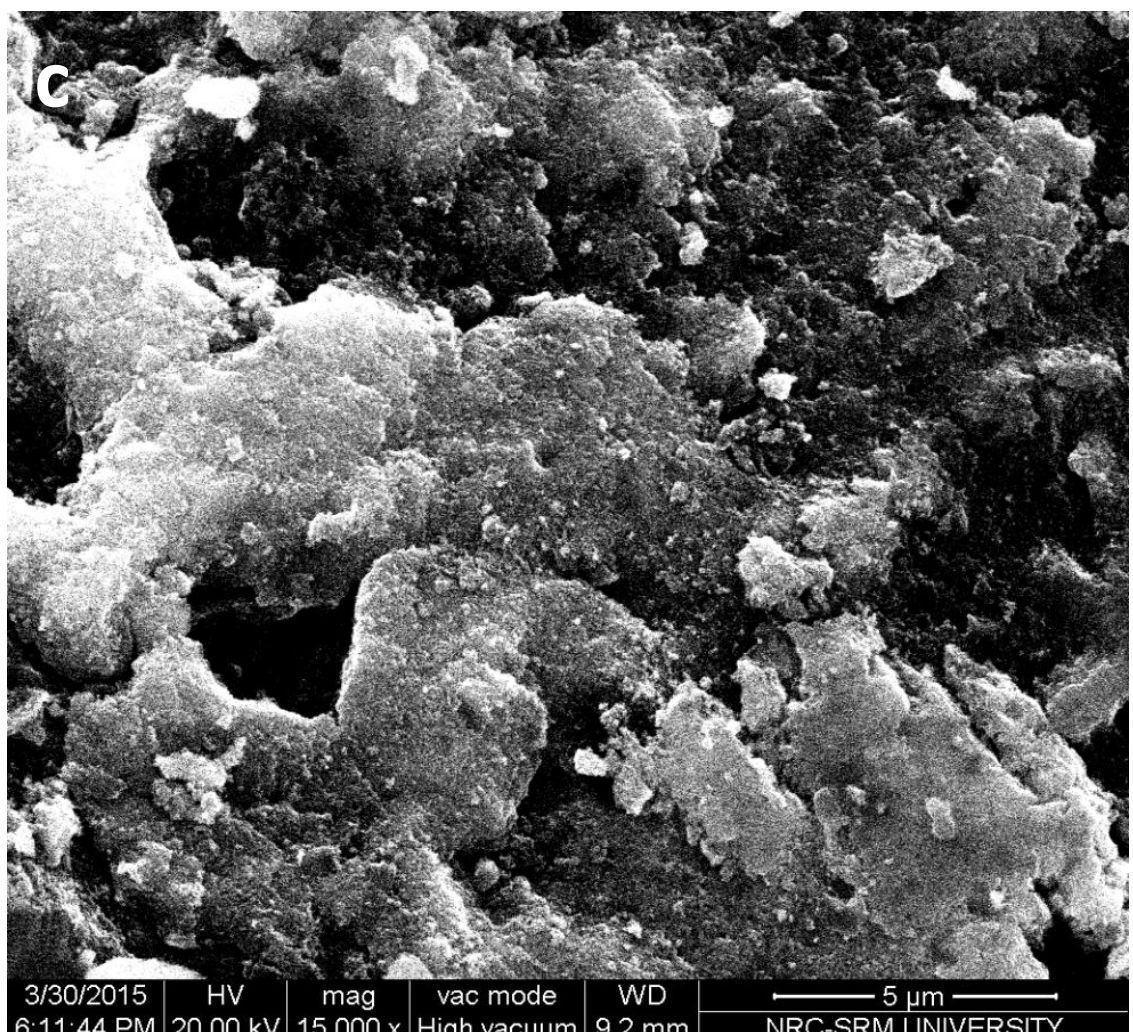

Figure 3. SEM image of (a) GSAC, (b) GSAC- $\mathrm{Fe}_{3} \mathrm{O}_{4}$, and (c) $\mathrm{GSAC}^{-} \mathrm{Fe}_{3} \mathrm{O}_{4}-\mathrm{MB}$

\subsection{Effect of $\mathrm{pH}$}

$\mathrm{pH}$ of the solution is a paramount controlling factor throughout the adsorption process, particularly on the adsorption capacity. The $\mathrm{pH}$ was determined at room temperature using a portable $\mathrm{pH}$ meter (systronics made) and calibrated using 4.0 buffer tablet. In this experiment, $\mathrm{pH}$ values were adjusted from 3-11 using dilute solutions of hydrochloric acid and sodium hydroxide.Firstly, methylene blue dye is a cationic dye andas shown in figure 3, dye uptake was found to be increasing with increase in $\mathrm{pH}$. Low uptake at lower $\mathrm{pH}$ has been attributed to the fact that the surface charge of GSAC- $-\mathrm{Fe}_{3} \mathrm{O}_{4}$ may be positive, and hence hydrogen ions $\left(\mathrm{H}^{+}\right)$ compete with methylene blue (cationic dye) for adsorption sites in the adsorbent. However, at higher $\mathrm{pH}$, the situation was otherwise, as a significant higher uptake was recorded. This may be attributed to the fact that the surface charge of GSAC- $\mathrm{Fe}_{3} \mathrm{O}_{4}$ may be negative, and hence may be able to bind with the methylene blue (cationic dye) through electrostatic force of attraction.

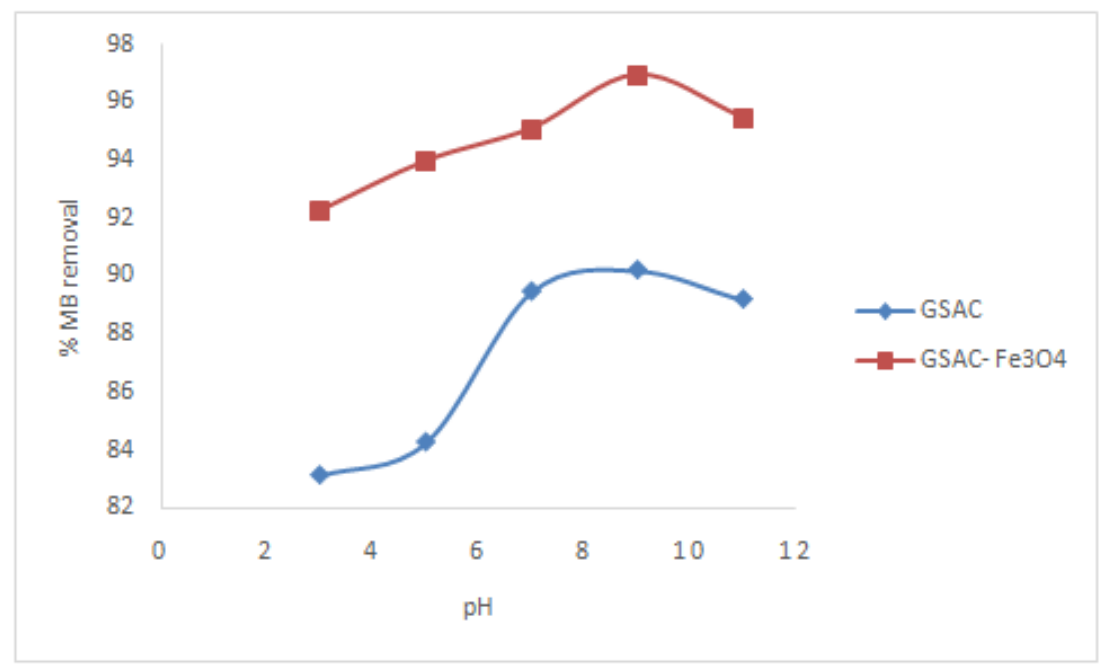

Figure 3. Effect of initial solution $\mathrm{pH}$ on the \% removal of $\mathrm{MB}$ 


\subsection{Effect of Initial Adsorbent Dosage}

Another parameter that is being used to assess the adsorption capacity of an adsorbent is the solid/solution ratio. In this experiment, the adsorption of methylene blue dye onto $\mathrm{GSAC}-\mathrm{Fe}_{3} \mathrm{O}_{4}$ was studied by varying the $\mathrm{GSAC}-\mathrm{Fe}_{3} \mathrm{O}_{4}$ dose $(0.1-0.5 \mathrm{~g} / 50 \mathrm{ml})$ for methylene blue dye concentration of $100 \mathrm{mgL}^{-1}$ at room temperature without changing the initial $\mathrm{pH}$.It can be clearly seen in figure 4 that the $\%$ removal of methylene blue dye increases with increase in $\mathrm{GSAC}-\mathrm{Fe}_{3} \mathrm{O}_{4}$ dose. This can be attributed to the fact that more active sites become available for adsorption with increase in $\mathrm{GSAC}-\mathrm{Fe}_{3} \mathrm{O}_{4}$ dose. A valid reason to support this is that, adsorption sites are unsaturated during adsorption while the number of sites for adsorption increases with increase in $\mathrm{GSAC}-\mathrm{Fe}_{3} \mathrm{O}_{4}$ dose.

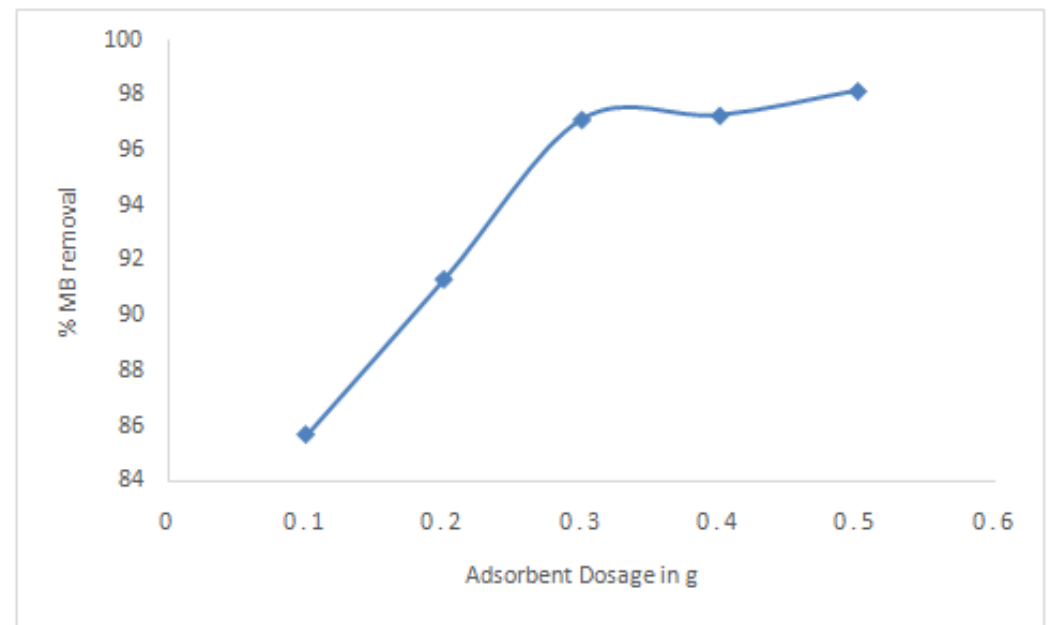

Figure 4. Effect of GSAC- $\mathrm{Fe}_{3} \mathrm{O}_{4}$ Dose on the \% removal of $\mathrm{MB}$

\subsection{Effect of Initial Dye Concentration}

This study was conducted by varying the initial dye concentration from $50-300 \mathrm{mgL}^{-1}$ at room temperature using same amount of $\mathrm{GSAC}-\mathrm{Fe}_{3} \mathrm{O}_{4}$ throughoutandwithout changing the initial $\mathrm{pH}$. As shown in figure 5, the percentage adsorption is higher at lower concentrations, and it keeps on decreasing with increase in the initial dye concentration, while the amount of methylene blue dye adsorbed per unit mass of GSAC-Fe $\mathrm{O}_{4}$ increases with increase in initial dye concentration. Thisis because, at low adsorbate/adsorbent ratio, there exists more available sites for adsorption, however, as the ratio increases, the sites becomes less/saturated, thereby decreasing the sorption efficiency. Hence, it can be concluded that the adsorption is highly dependent upon the initial concentration of the dye.

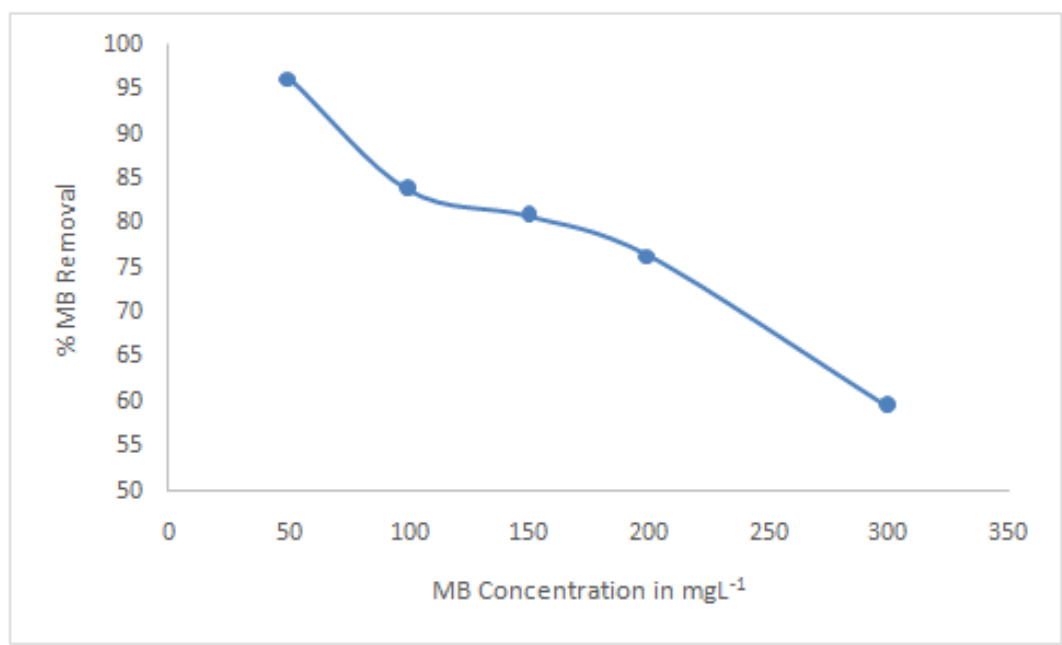

Figure 5. Effect of Initial Dye Concentration on the \% removal of MB

\subsection{Adsorption Isotherm}

The study of isotherms in adsorption is important for understanding how the molecules of the adsorbate interact with the adsorbent surface. In this study, Langmuir andFreundlich isotherms were tested. 


\subsubsection{Langmuir Isotherm}

The Langmuir isotherm is the most commonly used isotherm to represent data of adsorption from solution. Its basic assumption is that, adsorption takes place at specific homogeneous sites within the adsorbent ${ }^{[25]}$.The linearized form of the Langmuir isotherm is represented by equation (5):

$$
\frac{C_{e}}{q_{e}}=\frac{1}{K_{l} q_{m}}+\frac{C_{e}}{q_{m}}
$$

Where, $C_{e}$ is the equilibrium concentration of the adsorbate $\left(\mathrm{mgL}^{-1}\right), \mathrm{q}_{\mathrm{e}}$ is the amount of adsorbate adsorbed per unit mass of the adsorbent $(\mathrm{mg} / \mathrm{g}), \mathrm{q}_{\mathrm{m}}$ and $\mathrm{K}_{\mathrm{L}}$ is the Langmuir constants related to adsorption capacity and energy of adsorption. The values of $\mathrm{q}_{\mathrm{m}}$ and $\mathrm{K}_{\mathrm{L}}$ were determined from slope and intercepts of the plot and are presented in Table 1, respectively. The more the $\mathrm{R}^{2}$ value approaches unity, the more fitted the adsorption is to Langmuir isotherm ${ }^{[26]}$. A plot of $\mathrm{C}_{\mathrm{e}} / \mathrm{q}_{\mathrm{e}}$ against $\mathrm{C}_{\mathrm{e}}$ as shown in figure 6 , gave a straight line with a slope of $1 / \mathrm{q}_{\mathrm{m}}$ which clearly indicate conformity to the Langmuir isotherm.

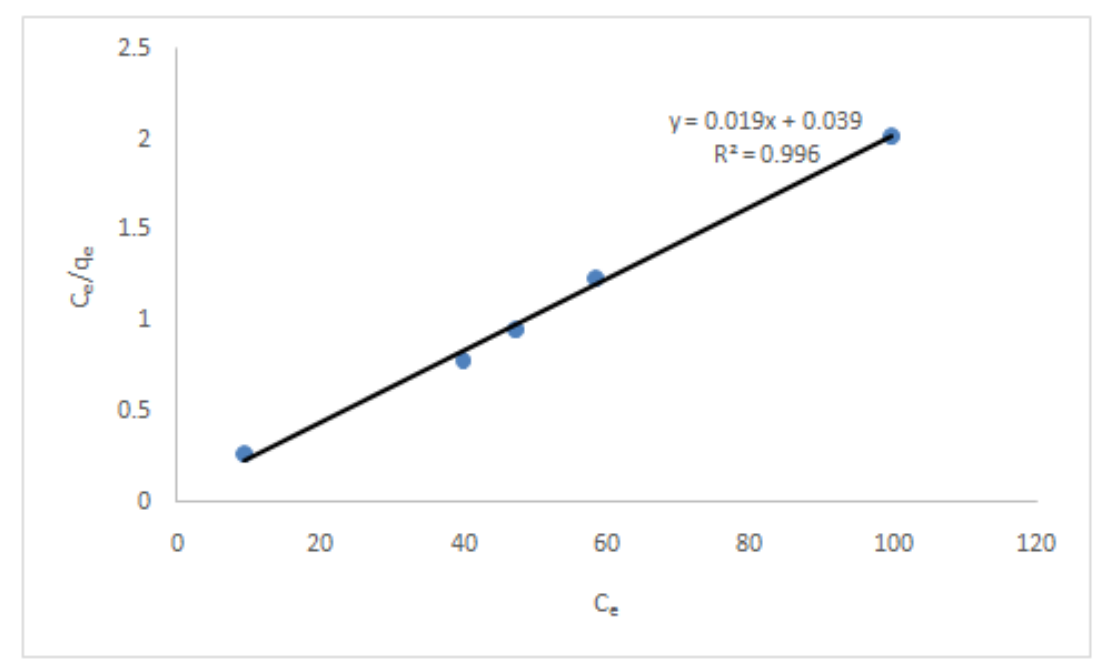

Figure 6. Langmuir Isotherm for the Adsorption of MB by GSAC- $\mathrm{Fe}_{3} \mathrm{O}_{4}$

\subsubsection{Freundlich Isotherm}

Another common isotherm that is been used to represent adsorption data is the Freundlich isotherm. Its basic assumption is that adsorption takes place on heterogeneous surface that has unequal adsorption sites with different energies of adsorption ${ }^{[1]}$. The linearized form of the Freundlich isotherm is represented by equation (7):

$$
\log q_{e}=\log K_{f}+\frac{1}{n} \log C_{e}
$$

Where $\mathrm{q}_{\mathrm{e}}$ is the amount of adsorbed at equilibrium $\left(\mathrm{mgg}^{-1}\right), \mathrm{C}_{\mathrm{e}}$ is the equilibrium concentration of dye in solution $\left(\mathrm{mgL}^{-1}\right) . \mathrm{K}_{\mathrm{f}}$ and $\mathrm{n}$ are Freundlich constants representing adsorption capacity and adsorption intensity or surface heterogeneity, respectively. Values of $\mathrm{K}_{\mathrm{f}}, 1 / \mathrm{n}$ andR $\mathrm{R}^{2}$ are shown in Table 1.The value of Freundlich coefficient $1 / \mathrm{n}$ ranging between 0 and lindicates favourable adsorption ${ }^{[27-28]}$.

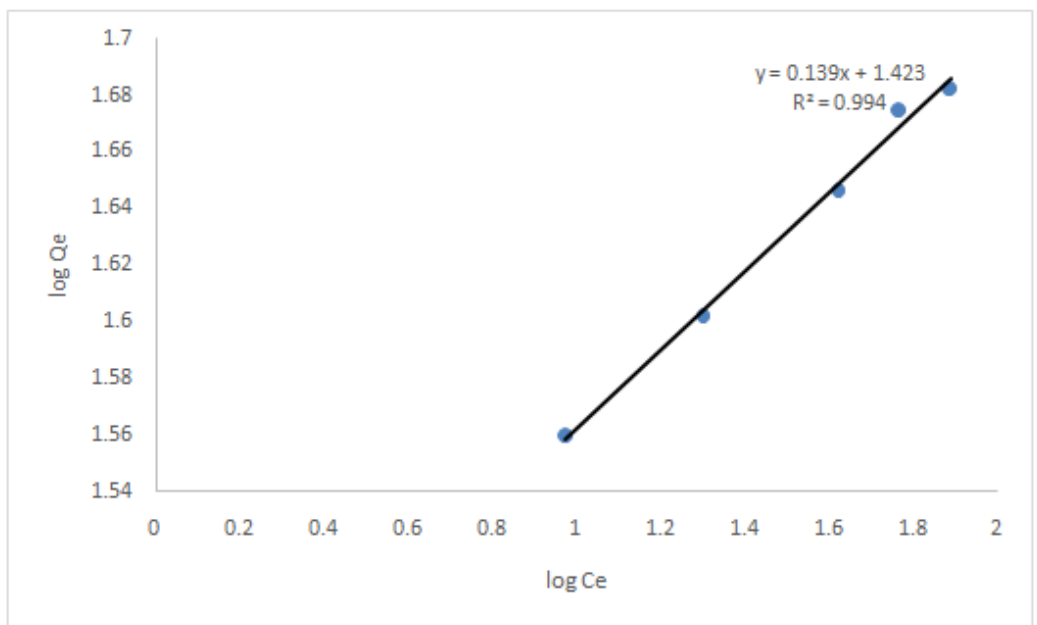

Figure 7. Freundlich Isotherm for the Adsorption of MB by GSAC- $\mathrm{Fe}_{3} \mathrm{O}_{4}$ 
Table 1. Isotherm Parameters for the Adsorption of MB by GSAC-Fe $\mathrm{O}_{4}$

\begin{tabular}{|l|l|l|l|l|l|}
\hline \multicolumn{2}{|l|}{ Langmuir Isotherm } & Freundlich Isotherm \\
\hline $\mathrm{qm}\left(\mathrm{mgg}^{-1}\right)$ & $\mathbf{K}_{\mathbf{L}}\left(\mathbf{m g L}^{-1}\right)$ & $\mathbf{R}^{2}$ & $\mathbf{K}_{\mathrm{f}}\left(\mathbf{m g g}^{-1}\right)$ & $\mathbf{1} / \mathbf{n}$ & $\mathbf{R}^{2}$ \\
\hline 50.51 & 0.5063 & 0.9963 & 26.49 & 0.1392 & 0.9945 \\
\hline
\end{tabular}

\subsection{Kinetic Studies}

Kinetic studies is avery important factor that determines the efficiency of adsorption. It is used to investigate the mechanism of adsorption of $\mathrm{MB}$ onto GSAC- $\mathrm{Fe}_{3} \mathrm{O}_{4}$. In this process, pseudo first order and pseudo second order kinetic models were applied to the experimental data to analyse the adsorption kinetics of $\mathrm{MB}$ onto GSAC- $\mathrm{Fe}_{3} \mathrm{O}_{4}$.

\subsubsection{Pseudo First Order Model}

The linear form of pseudo first order kinetic model, proposed by Lagergren is given below ${ }^{[29]}$ :

$$
\frac{d q_{t}}{d t}=k_{1}\left(q_{e}-q_{t}\right)
$$

Where, $\mathrm{q}_{\mathrm{e}}$ is the amount of dye adsorbed at equilibrium $\left(\mathrm{mg} \mathrm{g}^{-1}\right), \mathrm{q}_{\mathrm{t}}$ is the amount of dye adsorbed at time " $\mathrm{t}$ " $\left(\mathrm{mg} \mathrm{g}^{-1}\right), \mathrm{k}_{1}$ is the first order rate constant $\left(\mathrm{min}^{-1}\right)$ and $\mathrm{t}$ is the time $(\mathrm{min})$. Definite Integration of equation (8) within the boundary of $\mathrm{t}=0$ to $\mathrm{t}=\mathrm{t}$ and $\mathrm{q}_{\mathrm{t}}=0$ to $\mathrm{q}_{\mathrm{t}}=\mathrm{q}_{\mathrm{e}}$ gives equation (9);

$$
\log \left(q_{e}-q_{t}\right)=\log \dot{q}_{e}-\frac{k_{1}}{2.303} t
$$

Using the experimental results, a linear graph of $\log \left(\mathrm{q}_{\mathrm{e}}-\mathrm{q}_{\mathrm{t}}\right)$ versus time (t) was plotted, which was used to find $\mathrm{K}_{1}$ and $\mathrm{R}^{2}$ subsequently presented in Table 2 .

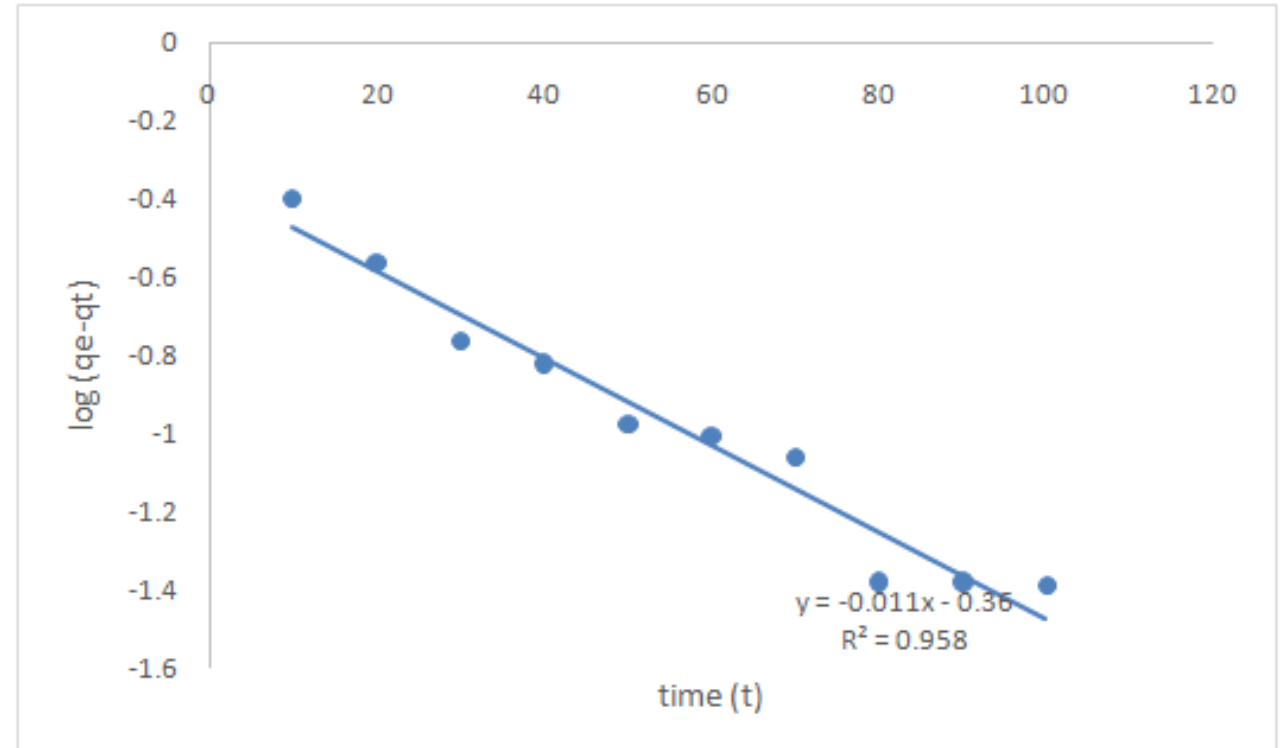

Figure 8. Pseudo First Order Kinetic Model Plot for the Adsorption of MB by GSAC-Fe $\mathrm{O}_{4}$

\subsubsection{Pseudo Second Order Model}

Another model that may be used to describe the kinetics of adsorption is the pseudo second order kinetic model. It was develop by $\mathrm{Ho}^{[30]}$ and is expressed as;

$$
\frac{d q_{t}}{d_{t}}=\mathrm{k}_{2}\left(q_{e}-q_{t}\right)^{2}
$$

Where $\mathrm{k}_{2}$ is the second order rate constant $\left(\mathrm{g} / \mathrm{mg} \mathrm{min}^{-1}\right)$. Definite Integration of equation (10) within the boundary of $\mathrm{t}=0$ to $\mathrm{t}=\mathrm{t}$ and $\mathrm{q}_{\mathrm{t}}=0$ to $\mathrm{q}_{\mathrm{t}}=\mathrm{q}_{\mathrm{e}}$ gives equation (11), which is the expression for the integrated linearized form of the pseudo second order kinetic model.

$$
\frac{t}{q_{t}}=\frac{1}{k_{2} q_{e}^{2}}+\frac{1}{q_{e}} t
$$

A plot of $t / q_{t}$ versus $t$ should to give a linear relationship, if at all, the adsorption process followed the pseudo second order kinetic model. The values of $\mathrm{q}_{\mathrm{e}}$ and $\mathrm{k}_{2}$ were determined from the slope and intercept, as presented in Table 2 respectively. 


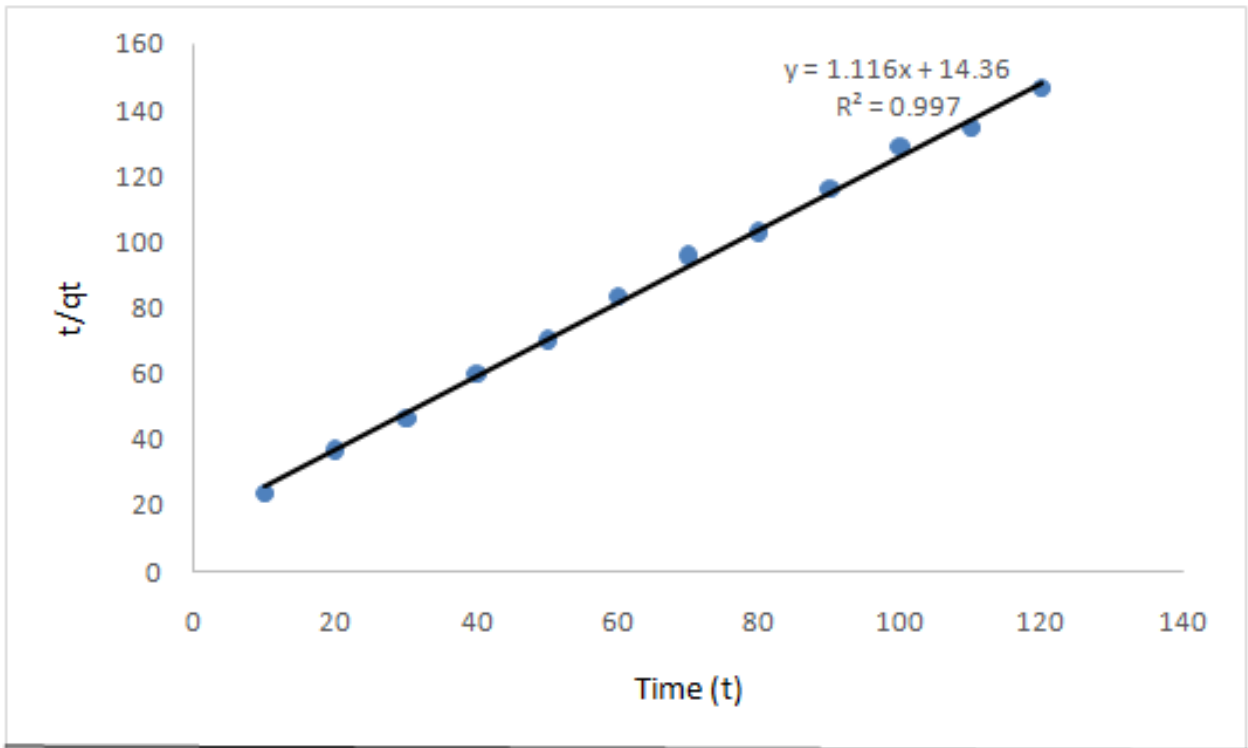

Fig. 9. Pseudo Second Order Kinetic Model Plot for the Adsorption of MB by GSAC- $\mathrm{Fe}_{3} \mathrm{O}_{4}$.

Table 1. Kinetic Parameters for the Adsorption of MB by GSAC-Fe ${ }_{3} \mathrm{O}_{4}$

\begin{tabular}{|l|l|l|l|l|l|}
\hline \multicolumn{4}{|l|}{ Pseudo First Order } & \multicolumn{2}{l|}{ Pseudo Second Order } \\
\hline $\mathrm{qe}\left(\mathrm{mgg}^{-1}\right)$ & $\mathbf{K}_{\mathbf{1}}\left(\mathbf{m i n}^{-1}\right)$ & $\mathbf{R}^{\mathbf{2}}$ & $\mathbf{q}_{\mathbf{e}}\left(\mathbf{m g g}^{-1}\right)$ & $\mathbf{K}_{\mathbf{2}}\left(\mathbf{g}^{-1} \mathbf{m g} \mathbf{~ m i n}\right)$ & $\mathbf{R}^{\mathbf{2}}$ \\
\hline 0.4365 & 0.0258 & 0.9584 & 0.8955 & 0.1392 & 0.9978 \\
\hline
\end{tabular}

\section{Conclusion}

The results of different experiments shows that groundnut shell activated carbon coated with $\mathrm{Fe}_{3} \mathrm{O}_{4}$ $\left(\mathrm{GSAC}-\mathrm{Fe}_{3} \mathrm{O}_{4}\right)$ has the ability to adsorb methylene blue (MB) dye from aqueous solutions. Kinetic data were tested using pseudo-first order and pseudo-second order kinetic models. The kinetics of the adsorption process was found to follow pseudo-second order kinetic model as the correlation coefficient for the pseudo-second order kinetic model is higher than that of pseudo-first order kinetic model, likewise, the calculated $\mathrm{q}_{\mathrm{e}}$ agrees with the experimental $\mathrm{q}_{\mathrm{e}}$, indicating the applicability of pseudo-second order kinetic model. The applicability of pseudo-second order kinetic model implies that the adsorption process was controlled by chemisorption. Equilibrium data best fitted to the Langmuir adsorption isotherm, confirming the monolayer adsorption of methylene blue (MB) dye onto groundnut shell activated carbon coated with $\mathrm{Fe}_{3} \mathrm{O}_{4}\left(\mathrm{GSAC}_{\mathrm{F}} \mathrm{Fe}_{3} \mathrm{O}_{4}\right)$. Hence, groundnut shell activated carbon coated with $\mathrm{Fe}_{3} \mathrm{O}_{4}\left(\mathrm{GSAC}-\mathrm{Fe}_{3} \mathrm{O}_{4}\right)$ has a good potential as a low cost adsorbent for improving the effectiveness of waste water treatment.

\section{Acknowledgements}

The authors are grateful to Nanotechnology Research Centre, SRM University for carrying out SEM analysis.

\section{References}

[1] Hossain, M. A., Hao, H. N., Guo, W. S. and Nguyen, T. V., Removal of Copper from Water by Adsorption onto Banana peel as Bioadsorbent. International Journal of Geomate; 2012, 2(2):227 - 234.

[2] Patil, A.K. and Shrivastava V.S., Alternantherabettzichiana Plant Powder as Low Cost Adsorbent for Removal of Congo Red from Aqueous Solution. International Journal of Chem Tech Research; 2010, 2(2): 842 - 850.

[3] Boyer, B., Cardoso, N.F., Lima, E.C., and Macedo, T.R., A Useful Organofunctionalized Layered Silicate for Textile Dye Removal. Journal Hazardous Materials; 2010, 181:366 - 374

[4] Kavitha, K. and Senthamilselvi, M.M., Adsorptive Removal of Methylene Blue using the Natural Adsorbent-Vitexnegundo Stem. International Journal of Current Research and Academic Review; 2014, 2(9): 270 - 280.

[5] Omotayo S.A., Akeem O.O., Abass O.A., Abolaji G.F. and Segun A.A., Adsorption of methylene Blue from Aqueous Solution, Using Steam-Activated Carbon produced Produced from Lantana camara stem. Journal of Environmental Protection; 2014, 5:1352 -1363 .

[6] Malik, P.K., Dye Removal from Wastewater Using Activated Carbon Developed from Sawdust: Adsorption Equilibrium and Kinetics. Journal of Hazardous Materials; 2004, 113:81 - 88.

[7] Crini, G., Non-conventional low cost adsorbents for dye removal: a review, Bioresour. Technol.; $2006,97: 1061$.

[8] Jumasiah A., Chuah T.G., Gimbon J., Choong T.S.Y. and Azni I., Adsorption of Basic Dye onto Palm Kernel Shell Activated Carbon: Sorption Equilibrium and Kinetics, Desalination; 2005, 186:57 - 64.

[9] Preethi S., Sivasamy A., Sivanesan S., Ramamurthi V. and Swaminathan G., Removal of Safranin Basic Dyefrom Aqueous Solution by Adsorption onto Corncob Activated Carbon. Ind. Eng. Chem. Res.; 2006, 45:7627 - 7632.

[10] Kumar K.V. and Kumaran A., Removal of Methylene Blue by Mango Seed Carnel Powder, Biochem Eng. Journal; $2005,27: 83$. 
[11] Indira K., Removal of Methylene Blue Dye from Aqueous Solutions by Neem Leaf and Orange Peel Powder, International Journal of Chem Tech Research.; 2013, 5: 572 - 577.

[12] Mane R.S. and Bhusari V.N., Removal of Dyes from Textile Effluent by Adsorption using Orange and Banana Peel, International Journal of Engineering Research and Applications.; 2012, 2: 1997 - 2004.

[13] Ahmad, A.A., Hameed, B.H. and Aziz, N., Adsorption of direct dye on palm ash: kinetic and equilibrium modeling. Journal of Harzardous Materials, 2006, 094, 1-10.

[14] Vien D., Colthup N.B., Fateley W.G., and Grasselli J.C., The Handbook of Infrared and Raman Characteristic Frequencies of Organic Molecules, Academic Press, San Diego, USA, 1991.

[15] Kapoor A., and Viraragavan T., Heavy Metal BiosorptionSites in Aspergillusniger, Bioresour. Technol; 1998, 61: $221-227$.

[16] Yun Y.S., Park D., Park J.M., and Volskey B., Biosorption of Trivalent Chromium on the Brown Seaweed Biomass, Environ. Sci. Technol; 2001, 35: 4353-4358.

[17] Pandey K.K. and Pitman A.J., FTIR Studies of the Changes in Wood Chemistry Following Decay by Brown-Rot and White-Rot Fungi. International Biodeterioration and Biodegradation; 2003, 52:151-160.

[18] Jeffrey A.B. and Ronaid J.S., Chemical Composition and Bioavailability of Thermally Altered Pinusresi-nosa (Red Pine). Wood Organic Geochemistry; 2002, 33:1093- 1109.

[19] Gong R.M., Sun Y.Z. and Chen J., Effect of Chemical Modification on Dye Adsorption Capacity of Peanut Hull. Dyes and Pigments; 2005, 67:175-181.

[20] Jain R. and Shrivastava M., Adsorptive Studies of Hazardous Dye TropaeolinefromanAqueousPhase onto Coconut-Husk. Journal of Hazardous Materials, 2008, 158:549-556.

[21] DermirbasA., Agricultural Based Activated Carbons for the Removal of Dyes from Aqueous Solutions: A Review. Journal of Hazardous Materials, 2009, 167:1-9.

[22] Kavitha D. and Namasivayam C., Experimental and Kinetic Studies on Methylene Blue Adsorption by Coir Pith Carbon. Bioresource Technology, 2007, 98:14-21.

[23] Bello O.S. and Ahmad M.A., Adsorption Removal of a Synthetic Textile Dye using Cocoa Pod Husk. Toxicological and Environmental Chemistry, 2011,93, 1298-1308.

[24] Khattari S.D. and Singh M.K., Removal of Malachite Green from Dye Waste Water Using Neem Saw Dust by Adsorption. Journal of Hazardous Materials, 2009, 167, 1089-1094.

[25] Bouberka Z., Khenifi A., Benderdouche N., Derriche Z., Removal of Supranol Yellow 4GL by adsorption onto Cr-intercalated montmorillonite, Journal of Hazardous Materials, 2006, 133, 154-161.

[26] Hossain M.A., Hao H.N., Guo W.S. and Nguyen T.V., Removal of Copper from Water by Adsorption onto Banana peel as Bio adsorbent. International Journal of Geomate, 2012, 2(2), 227 - 234.

[27] Donmez G. and Akzu Z., Removal of Chromium (VI) from Saline wastewater by Donleili species. Process Biochemistry, 2002, 38, 751-762.

[28] Patil A.K. and Shrivastava V.S., Alternantherabettzichiana Plant powder as Low Cost Adsorbent for Removal of Congo red from Aqueous Solution. International Journal of ChemTech Research, 2010, 2(2), 842 - 850.

[29] Syed Shabudeen, P. S., Daniel, S. and Indhumathi, P., Utilising the Pods of Delonixregia Activated Carbon for the Removal of Mercury (II) by Adsorption Technique Int. J. Res. Che. \&Environ., 2013, 3, 60-65.

[30] Vikal G., Jaya A., Manisha P., and Veena, Adsorption studies of Cu(II) from aqueous medium by Tamarind Kernal Powder. Res. J. Chem. Environ., 2007, 11(1), 40-43.

[31] Alaa R. Omran, Maysam A. Baiee, Sarab A. Juda, Jasim M. Salman, Ayad F. AlKaim, Removal of Congo red dye from aqueous solution using new adsorbent surface developed from aquatic plant(Phragmitesaustralis), International Journal of ChemTech Research 2016, 5(9), 334-342.

[32] SwapnaSundari, AsadollahKariman, Hamid Reza Mansouri, FatemehKariman, The Effectiveness of natural, Lowcost adsorbent for the removal of methylene blue, International Journal of ChemTech Research 2015,7(6), 2763-2768.

[33] Basker A., Syed Shabudeen P.S., Sequestration of Methylene Blue and Malachite Green from Aqueous Solution using Areca Husk Carbon, International Journal of ChemTech Research 2014, 6(11), 4894-4903.

[34] Yamuna, M., Kamaraj. M., Pineapple peel waste activated carbon as an adsorbent for the effective removal of methylene blue dye from aqueous solution, International Journal of ChemTech Research 2014, 9(5), 544-550.

[35] Maryam A., Mamoly L., Studying the use of vegetable waste (pineandcypresscones) as adsorbent in industrial water purification, International Journal of ChemTech Research 2015, 7(4), 2051-2053.

[36] Kalpana P., Bhagyalakshmi K., Rakesh N., Removal of Methylene blue from aqueous solution by Anthacephalouscadamba based activated carbon: Process Optimization using Response Surface Methodology (RSM), International Journal of ChemTech Research 2016, 9(8), 236-245.

[37] AseelAljeboree M., Adsorption of crystal violet dye by Fugas Sawdust from aqueous solution, International Journal of ChemTech Research 2016, 9(3), 412-423. 